\title{
Multivariate Analysis of Genetic Diversity Among Okra (Abelmoschus spp.) Cultivars Grown in Côte d'Ivoire Based on Agro-morphological Traits
}

\author{
N'Guessan Olivier Konan ${ }^{1 *} \quad$ Loh Tindé Maria Gbadé ${ }^{1} \quad$ N'Doua Paul Affian ${ }^{1}$ \\ Saïdou Diallo Mamadou ${ }^{1}$ Doffou Sélastique Akaffou ${ }^{1}$ Guy Mergeai ${ }^{2}$ \\ 1.Laboratory of Crop Improvement, Agroforestry Unit, Jean Lorougnon Guédé University, BP 150 Daloa, Côte \\ d'Ivoire \\ 2.Laboratory of Tropical Agroecology, Gembloux Agro-Bio Tech, Liège University, 2 passage des Déportés, \\ B-5030 Gembloux, Belgium
}

\begin{abstract}
Crop improvement for sustainable agriculture requires information about the genetic variability of traits that helps identify suitable parents. This study was conducted to investigate the extent of genetic diversity among 12 okra cultivars grown and marketed in Côte d'Ivoire, using 12 quantitative and 11 qualitative agro-morphological traits. A Randomized Complete Block Design (RCBD) with five replications and two multivariate techniques, viz. principal component analysis (PCA) and cluster analysis (CA) were used. The okra cultivars evaluated showed wide variation in quantitative traits but minimal variation in qualitative traits except for leaf and fruit shapes. The first two PCs explained $70.489 \%$ variation and identify seven traits (day to flowering, stem diameter, plant height, number of fruit ridges, number of fruits per plant, fruit yield and number of seeds per fruit) that play a prominent role in the differentiation of the okra cultivars, and therefore could be used as good criteria for selection in okra improvement. PCA and CA grouped the total cultivars into three divergent clusters exhibiting specific characteristics: vigor and good yield for cluster I, short plants and earliness for cluster II and high yield for cluster III. The results of this investigation indicated that substantial variability was present in the okra studied. The cultivars of the divergent clusters constitute interesting okra genetic resources that can be used as a parental material for further breeding.
\end{abstract}

Keywords: genetic diversity, okra, Abelmoschus caillei, Abelmoschus esculentus, principal component analysis, cluster analysis

DOI: $10.7176 / \mathrm{JBAH} / 10-22-03$

Publication date: November $30^{\text {th }} 2020$

\section{Introduction}

Okra is an important vegetable crop widely grown in the tropical and subtropical regions of the world (Syfullah et al. 2018). It is mainly cultivated for its tender immature fruits and fresh leaves used in many cuisines and preparations for human consumption (Oppong-Sekyere et al. 2018). This vegetable has a significant nutritional value and it provides an important input of dietary fibres, carbohydrates, vitamins, minerals, and antioxidant substances (Marcelline et al. 2018). Its dried seeds are rich in high-quality edible oil (13-22\%) and proteins (2024\%), and in some countries they are roasted, ground and used as a substitute for coffee (Kumari et al. 2019).

Okra belongs to the family Malvaceae and the genus Abelmoschus (Adeoluwa \& Kehinde 2011). There are eight species in this genus of which A. esculentus (L.) Moench and A. caillei (A. Chev.) Stevels are the main cultivated species (Ogwu et al. 2018). Four of the remaining species (A. angulosus Wall. ex Wight \& Arn., A. crinitus Wall., A. tetraphyllus Wall., and A. ficulneus (L.) Wight \& Arn.) are wild and two (A. manihot (L.) Medik. and A. moschatus Medik.) are semi-cultivated (Ogwu et al. 2018). The two main cultivated okra, A. esculentus and A. caillei, are native of Asia and Africa, respectively (Adeoluwa \& Kehinde 2011). The Asian species (A. esculentus) also referred to as common okra is now cultivated throughout the world and accounts for $95 \%$ of okra cultivated area globally; while the African okra (A. caillei) is primarily cultivated in Africa and accounts for $5 \%$ cultivated area (Ahiakpa et al. 2017).

The world okra production was estimated at $9872826 \mathrm{~T}$ in 2018 (FAOSTAT 2020). The three highest okra producing countries in the year 2018 were India (6 126000 T), Nigeria (2 033129 T) and Sudan (304 712 T) (FAOSTAT 2020).

In Côte d'Ivoire, okra can be found in nearly every market and it has a vital importance as food diet among the inhabitants of the cities and villages. The Ivoirian production in 2018 was $160250 \mathrm{~T}$ (FAOSTAT 2020). In this country, okra constitutes an important economic crop with high socioeconomic and nutritional relevance for the population. The cultivation and commercialization of this vegetable can potentially contribute to poverty reduction. However, okra has long been considered in Côte d'Ivoire a minor crop, and little effort has been devoted to its genetic improvement. The production of the country is below demand, and the need of improved varieties well adapted to local conditions is a challenge for breeders today. 
For crop improvement, one important aspect is assessment of genetic diversity (Amiteye et al. 2019). It is a key factor from which useful characters can be detected and used for selection of suitable parents for breeding programs (Syfullah et al. 2018). In Côte d'Ivoire, there is limited information about the genetic diversity of okra germplasm currently cultivated. There is a need of a better understanding of the extent of genetic diversity among the available okra cultivars. In this regard, the use of multivariate analyses based on agro-morphological traits is very essential and can help to pave way for genetic improvement of this crop (Binalfew \& Alemu 2016). Actually, genetic diversity evaluation based on agro-morphological traits still remains a very useful technique highly recommended as the first step to be adopted in any crop improvement program prior to more in depth molecular or biochemical studies (Amiteye et al. 2019; Temam et al. 2020).

Hence, the objective of the present study was to determine the genetic diversity and genetic relationships among okra cultivars grown in Côte d'Ivoire using agro-morphological descriptors, in order to generate information that could potentially help breeders to improve the crop.

\section{Materials and methods}

\subsection{Experimental Site}

The work was carried out in Zépréguhé, a village located in the center-west of Côte d'Ivoire, $130 \mathrm{~km}$ from the capital Yamoussoukro. The area was under humid tropical conditions with $1317 \mathrm{~mm}$ of rainfall per year and relative dense forest vegetation. The experiment site was located $6^{\circ} 90 \mathrm{~N}$ latitude and $6^{\circ} 37 \mathrm{~W}$ with an altitude of 238 m.a.s.l. (above sea level). The soil of the plot was sandy loam texture with good fertility, properly leveled and well drained. The mean temperature and relative humidity during the experiment period ranged from 25 to $35^{\circ} \mathrm{C}$ and 69 to $83 \%$, respectively.

\subsection{Plant Materials}

A total of 12 okra cultivars grown and marketed in Côte d'Ivoire (Table 1) were evaluated in this study. This germplasm included nine cultivars of $A$. esculentus and three local cultivars of $A$. caillei.

\subsection{Experimental Design}

The experiment was conducted in Randomized Complete Block Design (RCBD) with five replications. The spacing between adjacent replications was $2 \mathrm{~m}$. Three seeds per hill were sown at a depth of $3 \mathrm{~cm}$ and thinned to one plant per hill when plants reached 3-4 leaves stage. Each cultivar was raised in a single-row plot with a rowto-row spacing of $100 \mathrm{~cm}$ and plant-to-plant spacing of $80 \mathrm{~cm}$. A plant population of 5 plants per row, plot and cultivar was maintained. Thus, each cultivar was represented by 25 individual plants, i.e. 300 plants for the overall 12 cultivars on the experiment field.

Table 1. List of okra cultivars studied.

\begin{tabular}{|l|l|l|}
\hline No & Cultivar & Species \\
\hline 1 & Hiré & A. esculentus (L.) Moench \\
2 & Kirikou & A. esculentus (L.) Moench \\
3 & Yelen & A. esculentus (L.) Moench \\
4 & Volta & A. esculentus (L.) Moench \\
5 & Yodana & A. esculentus (L.) Moench \\
6 & kousko & A. esculentus (L.) Moench \\
7 & Cali & A. esculentus (L.) Moench \\
8 & Emerald & A. esculentus (L.) Moench \\
9 & Clemson & A. esculentus (L.) Moench \\
10 & Locale\#1 & A. caillei (A.Chev.) Stevels \\
11 & Locale\#2 & A. caillei (A.Chev.) Stevels \\
12 & Locale\#3 & A. caillei (A.Chev.) Stevels \\
\hline
\end{tabular}

\subsection{Field Managements}

Standard agronomic and management practices were adopted to raise a healthy crop, but no fertilizer was applied. Daily watering using a watering can was applied uniformly to all plots, until harvest to allow the okra to complete its cycle. Manual weeding by hoeing and handpicking were carried out when necessary to avoid any competition between the crop and the weeds, and thus allow better crop development. 


\subsection{Data Collection}

Data were collected on five plants of each cultivar in each replication. These Data concerned 12 quantitative and 11 qualitative traits recorded on the plants using the descriptor list for okra species established by the International Plant Genetic Resources Institute (IPGRI 1991), currently named Biodiversity International. For the data collection, visual observations and measurements were done. The following agro-morphological characters were evaluated: - Quantitative traits: days to emergence (DE), days to flowering (DF), plant height at flowering (PH), stem diameter at base (SD) at flowering, fruit length at maturity (FL), fruit diameter at maturity (FD), number of ridges per fruit (FR), average fresh fruit weight (FW), number of fruits per plant (FNP), fresh fruit yield per plant (FYP), average number of seeds per fruit (SN), 100 seed weight (100SW).

- Qualitative traits: plant general aspect (PA), branching habit (BH), stem pubescence (SP), stem colour (SC), leaf colour (LC), leaf shape (LS), petal colour (PC), fruit position from the main stem (FPS), fruit colour (FC), fruit shape (FS), fruit pubescence (FP).

\subsection{Statistical Analysis of Data}

Microsoft Excel Software (2007 edition) was used to compile the data and the software Statistica 7.1 was used for statistical analyses. The means and the standard errors were calculated and the data were subjected to Analysis of Variance (ANOVA) to determine the presence of statistically significant differences among cultivars for the traits measured. A p-value of 0.05 or less was considered statistically significant. The least significant difference (LSD) test was used to separate significantly different means. The variables were also subjected to two methods of multivariate analyses: Principal Component Analysis (PCA) and Cluster Analysis (CA).

PCA was done to transform the original variables into a limited number of uncorrelated new variables and to allow the visualization of differences among cultivars, the identification of groups, and the identification of relationships among cultivars and variables. The Eigen Values and Eigen Vectors were computed, which represent the variance and the loadings of the corresponding principal components (PCs). A biplot analysis was carried out based on the two most important PCs to visualize the pattern of total diversity within the germplasm studied. The degree of correlation between the traits and the percentage contribution of each trait to the total diversity were determined.

CA was used to group the accessions into various clusters according to genetic distance. The clustering was performed using the genetic distances computed from quantitative and qualitative traits. The Manhattan distance (or city-block) was used. The distance matrix was used to construct a dendrogram based on the Unweighted Pairgroup Method with Arithmetic Means (UPGMA). The genetic relationships among the cultivars and the distances between and within the clusters were determined and analyzed.

\section{Results}

3.1 Variation in Crop Phenology and Growth Traits

For the okra cultivars studied, the mean values of days to seedling emergence, days to flowering, stem diameter and plant height are presented in Table 2.

Table 2. Mean value and standard error of the phenological and growth traits of the 12 okra cultivars.

\begin{tabular}{|l|cccc|}
\hline Cultivar & DE (day) & DF (day) & SD (cm) & PH (cm) \\
\hline Hiré & $5.043^{\mathrm{cde}} \pm 0.242$ & $57.565^{\mathrm{c}} \pm 2.194$ & $1.142^{\mathrm{bc}} \pm 0.119$ & $39.087^{\mathrm{cd}} \pm 2.534$ \\
Kirikou & $5.583^{\mathrm{def}} \pm 0.237$ & $58.917^{\mathrm{c}} \pm 2.148$ & $1.190^{\mathrm{c}} \pm 0.117$ & $41.250^{\mathrm{d}} \pm 2.481$ \\
Yelen & $5.708^{\mathrm{ef}} \pm 0.237$ & $57.542^{\mathrm{c}} \pm 2.148$ & $1.288^{\mathrm{c}} \pm 0.117$ & $37.000^{\mathrm{cd}} \pm 2.481$ \\
Volta & $5.000^{\mathrm{cd}} \pm 0.260$ & $61.850^{\mathrm{c}} \pm 2.353$ & $1.291^{\mathrm{c}} \pm 0.128$ & $34.000^{\mathrm{bcd}} \pm 2.718$ \\
Yodana & $4.500^{\mathrm{c}} \pm 0.248$ & $61.727^{\mathrm{c}} \pm 2.244$ & $1.131^{\mathrm{bc}} \pm 0.122$ & $34.136^{\mathrm{bc}} \pm 2.591$ \\
Kousko & $2.000^{\mathrm{a}} \pm 0.237$ & $42.583^{\mathrm{a}} \pm 2.148$ & $0.819^{\mathrm{ab}} \pm 0.117$ & $24.583^{\mathrm{a}} \pm 2.481$ \\
Cali & $2.947^{\mathrm{b}} \pm 0.267$ & $45.474^{\mathrm{ab}} \pm 2.414$ & $0.697^{\mathrm{a}} \pm 0.131$ & $22.842^{\mathrm{a}} \pm 2.788$ \\
Emerald & $3.000^{\mathrm{b}} \pm 0.291$ & $49.813^{\mathrm{b}} \pm 2.631$ & $0.805^{\mathrm{ab}} \pm 0.143$ & $28.438^{\mathrm{ab}} \pm 3.038$ \\
Clemson & $6.143^{\mathrm{f}} \pm 0.439$ & $65.571^{\mathrm{c}} \pm 3.978$ & $0.984^{\mathrm{abc}} \pm 0.216$ & $32.429^{\mathrm{abcd}} \pm 4.593$ \\
Local\#1 & $7.500^{\mathrm{g}} \pm 0.411$ & $97.125^{\mathrm{e}} \pm 3.721$ & $2.376^{\mathrm{d}} \pm 0.202$ & $55.500^{\mathrm{e}} \pm 4.297$ \\
Local\#2 & $5.727^{\mathrm{f}} \pm 0.248$ & $83.818^{\mathrm{d}} \pm 2.244$ & $2.332^{\mathrm{d}} \pm 0.122$ & $59.147^{\mathrm{e}} \pm 2.591$ \\
Local\#3 & $6.118^{\mathrm{f}} \pm 0.282$ & $110.647^{\mathrm{f}} \pm 2.553$ & $2.529^{\mathrm{d}} \pm 0.139$ & $59.529^{\mathrm{e}} \pm 2.948$ \\
\hline Mean & $4.939 \pm 0.283$ & $66.053 \pm 2.565$ & $1.382 \pm 0.139$ & $38.995 \pm 2.962$ \\
\hline
\end{tabular}

Means with same superscript letters in each column of the table are not significantly $(\mathrm{P}>0.05)$ different from one another. DE: days to emergence; DF: days to flowering; SD: stem diameter at base; PH: plant height at flowering. 
There were significant differences in the mean number of days taken for seedlings of the 12 cultivars to emerge. The mean values ranged from 2 to 7.2 days with an average of 4.939 days. The cultivars Local\#1, Local\#3 and Local\#2 of the species A. caillei took the longest average number of days to emerge $(7.5,6.118$ and 5.727 days respectively) while the cultivars Kousko, Cali and Emerald of the species $A$. esculentus recorded the shortest average number of days $(2,2.947$ and 3 respectively). Number of days to flowering differed significantly among the 12 cultivars of okra evaluated. The mean values for days to flowering ranged from 42.583 to 110.647 days. The cultivars Local\#3, Local\#1 and Local\#2 again took the highest mean number of days to flowering $(110,97.125$ and 83.818 days, respectively), while the cultivars Kousko, Cali and Emerald showed the shortest mean number of days (42.283, 45.474 and 49.813 days, respectively).

Growth parameters differed significantly among the okra accessions. The tallest plants were recorded for cultivars Local\#3, Local\#1 and Local\#2 with mean values of $59.529,59.147$ and $55.500 \mathrm{~cm}$ respectively. The least values were recorded for Cali, Kousko, and Emerald with mean values of 22.842, 24.583 and $28.438 \mathrm{~cm}$, respectively. The three local cultivars Local\#3, Local\#1 and Local\#2 also had the highest values of stem diameter with $2.529,2.376$ and $2.332 \mathrm{~cm}$ respectively. The finest stems were shown by Cali, Emerald and Kousko with $0.697,0.805$ and $0.819 \mathrm{~cm}$, respectively.

\subsection{Variation in Quantitative Traits of the Fruits}

The values of the quantitative parameters of the fruit (fruit length, fruit diameter, fruit weight, number of ridges per fruit) are presented in Table 3.

Table 3. Mean value and standard error of fruit traits of the 12 okra cultivars.

\begin{tabular}{|l|cccc|}
\hline Cultivar & FL $\mathbf{( c m )}$ & FD $\mathbf{( c m})$ & FR & FW (g) \\
\hline Hiré & $7.135^{\mathrm{ef}} \pm 0.345$ & $2.561^{\mathrm{cd}} \pm 0.090$ & $7.391^{\mathrm{cd}} \pm 0.152$ & $33.057^{\mathrm{de}} \pm 3.024$ \\
Kirikou & $5.825^{\mathrm{cd}} \pm 0.338$ & $2.254^{\mathrm{b}} \pm 0.088$ & $7.429^{\mathrm{cd}} \pm 0.1472$ & $29.678^{\mathrm{cde}} \pm 3.024$ \\
Yelen & $4.775^{\mathrm{ab}} \pm 0.338$ & $2.700^{\mathrm{d}} \pm 0.088$ & $7.583^{\mathrm{de}} \pm 0.149$ & $29.249^{\mathrm{cde}} \pm 3.024$ \\
Volta & $7.588^{\mathrm{f}} \pm 0.413$ & $1.869^{\mathrm{ab}} \pm 0.108$ & $7.000^{\mathrm{bc}} \pm 0.172$ & $16.583^{\mathrm{a}} \pm 3.024$ \\
Yodana & $6.353^{\mathrm{cde}} \pm 0.379$ & $2.242^{\mathrm{b}} \pm 0.099$ & $7.950^{\mathrm{e}} \pm 0.163$ & $24.590^{\mathrm{abcd}} \pm 3.024$ \\
Kousko & $5.500^{\mathrm{bc}} \pm 0.523$ & $2.330^{\mathrm{bc}} \pm 0.136$ & $6.571^{\mathrm{b}} \pm 0.195$ & $19.889^{\mathrm{abc}} \pm 3.904$ \\
Cali & $3.643^{\mathrm{a}} \pm 0.625$ & $2.657^{\mathrm{cd}} \pm 0.163$ & $5.000^{\mathrm{a}} \pm 0.236$ & $16.500^{\mathrm{a}} \pm 3.904$ \\
Emerald & $7.833^{\mathrm{ef}} \pm 0.955$ & $1.833^{\mathrm{a}} \pm 0.249$ & $5.000^{\mathrm{a}} \pm 0.364$ & $17.667^{\mathrm{ab}} \pm 3.904$ \\
Clemson & $7.667^{\mathrm{def}} \pm 0.955$ & $2.133^{\mathrm{abc}} \pm 0.249$ & $6.500^{\mathrm{b}} \pm 0.421$ & $31.00^{\mathrm{cde}} \pm 3.904$ \\
Locale\#1 & $6.0^{\mathrm{abcdef}} \pm 1.654$ & $4.300^{\mathrm{e}} \pm 0.431$ & $8.500^{\mathrm{e}} \pm 0.515$ & $32.50^{\mathrm{de}} \pm 4.781$ \\
Locale\#2 & $7.846^{\mathrm{f}} \pm 0.459$ & $3.554^{\mathrm{e}} \pm 0.119$ & $6.679^{\mathrm{b}} \pm 0.195$ & $27.0^{\mathrm{bcde}} \pm 3.381$ \\
Locale\#3 & $8.500^{\mathrm{f}} \pm 0.740$ & $3.580^{\mathrm{e}} \pm 0.193$ & $7.200^{\mathrm{bcd}} \pm 0.266$ & $33.533^{\mathrm{e}} \pm 3.024$ \\
\hline Mean & $6.555 \pm 0.644$ & $2.668 \pm 0.168$ & $6.900 \pm 0.248$ & $25.937 \pm 3.493$ \\
\hline
\end{tabular}

Means with same superscript letters in each column of the table are not significantly $(\mathrm{P}>0.05)$ different from one another. FL: fruit length at maturity; FD: fruit diameter at maturity; FR: number of ridges per fruit; FW: average fresh fruit weight.

Fruit length differed significantly among the 12 okra cultivars and ranged from 3.643 to $8.500 \mathrm{~cm}$. Fruit of Local\#3, Local\#2 and Volta gave the highest mean values (8.500, 7.846 and 7.588 respectively), while Cali and Yelen had the least mean values (3.643 and $4.775 \mathrm{~cm}$ respectively). Regarding the width of the fruit, there were also significant differences. It varied from 1.869 to $4.300 \mathrm{~cm}$. The three cultivars Local\#1, Local\#3 and Local\#2 had the widest fruits with mean diameters of 4.300, 3.580 and $3.554 \mathrm{~cm}$, respectively. The finest fruits were presented by Emerald and Volta with mean diameters of 1.833 and $1.869 \mathrm{~cm}$, respectively.

Fruit weight varied within a range of 16.50 to $33.533 \mathrm{~g}$. The heaviest fruits were produced by Local\#3 (33.533 g), Hiré (33.057 g) and Locale\#1 (32.500 g). The least heavy fruits were found in Cali (16.500 g) and Volta (16.583 g).

Concerning the fruit ridges, all the cultivars had ridges on the fruits even if the cultivars Emerald, Clemson, Local\#1 and Local\#3 did not have well-marked ridges on their fruits. The mean number of ridges per fruit varied from 5 to 8.50 with an average of 6.90. The fruits of Local\#1 and Yodana had the highest number of ridges $(8.50$ and 7.950 ridges on average, respectively). The lowest number of fruit ridges was found on fruits of Emerald and Cali with a mean value of 5 .

\subsection{Variation in Fruit and Seed Yields}

Table 4 presents the variability of the average number of fruits per plant, fruit yield per plant, seed number per 
fruit and 100 seed weight.

Table 4. Mean value and standard error of production and yield parameters of the 12 okra cultivars.

\begin{tabular}{|l|cccc|}
\hline \multicolumn{1}{|c|}{ Cultivar } & FNP & FYP $(\mathbf{g})$ & SN & $\mathbf{1 0 0 S W ( g )}$ \\
\hline Hiré & $3.826^{\mathrm{cd}} \pm 0.477$ & $126.260^{\mathrm{bcd}} \pm 13.790$ & $57.040^{\mathrm{c}} \pm 8.078$ & $3.717^{\mathrm{b}} \pm 0.357$ \\
Kirikou & $4.375^{\mathrm{cd}} \pm 0.467$ & $129.841^{\mathrm{bcd}} \pm 13.500$ & $59.320^{\mathrm{c}} \pm 8.078$ & $3.643^{\mathrm{b}} \pm 0.357$ \\
Yelen & $5.125^{\mathrm{d}} \pm 0.467$ & $149.906^{\mathrm{d}} \pm 13.500$ & $46.400^{\mathrm{bc}} \pm 8.078$ & $5.102^{\mathrm{c}} \pm 0.357$ \\
Volta & $2.350^{\mathrm{a}} \pm 0.512$ & $38.963^{\mathrm{a}} \pm 14.788$ & $42.600^{\mathrm{bc}} \pm 9.031$ & $3.497^{\mathrm{a}} \pm 0.399$ \\
Yodana & $3.818^{\mathrm{bcd}} \pm 0.488$ & $93.889^{\mathrm{b}} \pm 14.100$ & $46.150^{\mathrm{bc}} \pm 9.031$ & $3.710^{\mathrm{b}} \pm 0.399$ \\
Kousko & $1.958^{\mathrm{a}} \pm 0.467$ & $38.951^{\mathrm{a}} \pm 13.500$ & $46.522^{\mathrm{bc}} \pm 9.023$ & $3.500^{\mathrm{b}} \pm 0.399$ \\
Cali & $2.421^{\mathrm{ab}} \pm 0.525$ & $39.947^{\mathrm{a}} \pm 15.173$ & $44.333^{\mathrm{bc}} \pm 10.429$ & $2.900^{\mathrm{a}} \pm 0.461$ \\
Emerald & $1.813^{\mathrm{a}} \pm 0.572$ & $32.027^{\mathrm{a}} \pm 16.534$ & $36.533^{\mathrm{abc}} \pm 10.429$ & $2.550^{\mathrm{a}} \pm 0.461$ \\
Clemson & $2.714^{\mathrm{abc}} 0.865$ & $84.143^{\mathrm{abc}} \pm 24.998$ & $39.800^{\mathrm{abc}} \pm 9.031$ & $2.881^{\mathrm{a}} \pm 0.399$ \\
Locale\#1 & $2.625^{\mathrm{abc}} \pm 0.809$ & $85.313^{\mathrm{abc}} \pm 23.383$ & $20.000^{\mathrm{abc}} \pm 8.063$ & $3.000^{\mathrm{a}} \pm 0.798$ \\
Locale\#2 & $4.455^{\mathrm{cd}} \pm 0.488$ & $120.273^{\mathrm{bcd}} \pm 14.100$ & $10.300^{\mathrm{a}} \pm 12.772$ & $5.197^{\mathrm{c}} \pm 0.564$ \\
Locale\#3 & $4.059^{\mathrm{cd}} \pm 0.555$ & $136.092^{\mathrm{cd}} \pm 16.040$ & $15.800^{\mathrm{b}} \pm 18.063$ & $5.333^{\mathrm{c}} \pm 0.798$ \\
\hline Mean & $3.295 \pm 0.558$ & $89.634 \pm 16.117$ & $38.733 \pm 10.842$ & $3.753 \pm 0.479$ \\
\hline
\end{tabular}

Means with same superscript letters in each column of the table are not significantly $(\mathrm{P}>0.05)$ different from one another. FNP: number of fruits per plant; FYP: fresh fruit yield per plant; SN: average number of seeds per fruit; 100SW: 100 seed weight.

The number of fruits per plant ranged from 1.813 to 5.125 with a mean of 3.295. Yelen gave on average the highest number of fruits per plant (5.125 fruits). It was followed by Local\#2 (4.455 fruits), Kirikou (4.375 fruits), Local\#3 (4.059 fruits) and Hiré (3.826 fruits). The least productive cultivars were Emerald (1.813 fruits per plant), Kousko (1.958 fruits per plant) and Volta (2.350 fruits per plant). In terms of yield, Yelen had the highest value with $149.906 \mathrm{~g}$ marketable fruits per plant. Then came Local\#3 (136.092 g), Kirikou (129.841 g) and Hiré (126.260 g). The lowest values of fruit yield were recorded with Emerald (32.027 g), Kousko (38.951 g), Volta (38.963 g) and Cali (39.947 g).

There were significant differences in the average number of seeds per fruits among the cultivars of okra evaluated. The values ranged from 59.320 to 10.300 with an average of 38.733 . Kirikou and Hiré had the highest average number of seeds per fruit (59.320 and 57.040 respectively) while Locale\#2 had the lowest mean value (10.300). The 100 seed weights ranged from 2.550 to $5.333 \mathrm{~g}$. Locale\#3, Locale\#2 and Yelen had the highest weight of 100 seeds (5.333 g, $5.197 \mathrm{~g}$ and $5.102 \mathrm{~g}$, respectively), while the cultivars Volta, Locale\#1, Cali, Clemson and Emerald had the least values (3.497 g, $3.000 \mathrm{~g}, 2.900 \mathrm{~g}, 2.881 \mathrm{~g}$ and $2.550 \mathrm{~g}$ respectively).

\subsection{Variation in Qualitative Traits}

Most of the qualitative traits studied showed minimal variation with the exception of leaf and fruit shapes. For plant general aspect, apart from Cali which was procumbent, all the other cultivars have an erect aspect. Two types of branching habit were observed: moderately branched plants for most of the cultivars of $A$. esculentus, and relatively very branched plants for the three local cultivars of $A$. caillei.

At the level of stem pubescence, Hiré, Kirikou and Local\#1 had glabrous stems, while all the other cultivars had slightly pubescent stems. The colour of the stem was green for Volta, Yodana, Kousko and Local\#2, and green with red veins for the remaining cultivars.

Five types of leaf shapes were observed (Figure 1) based on the descriptors of the International Plant Genetic Resources Institute (IPGRI 1991): type 2 for Voltat and Yodana; type 3 for Kirikou and Yelen; type 4 for Hiré, Kousko, Locale\#1, Locale\#2 and Locale\#3; type 6 for Cali and Emerald; and type 10 for Clemson. The leaves were green for Volta and Clemson and green with red veins for the other cultivars. 


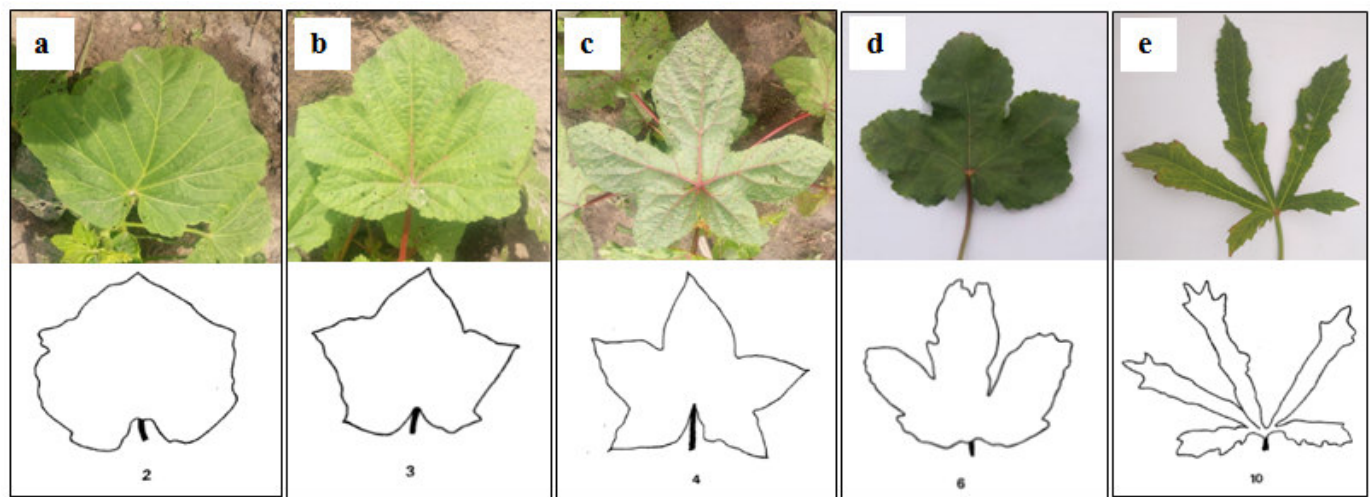

Figure 1. Different types of leaf shapes of the okra cultivars studied: a) Shape type 2: Voltat and Yodana; b) Shape type 3: Kirikou and Yelen; c) Shape type 4: Hiré, Kousko, Locale\#1, Locale\#2 and Local\#3; d) Shape type 6: Cali and Emerald; e) Shape type 10: Clemson.

Regarding the flowers, most of the cultivars had yellow petals with a red coloration at the base, except the three local cultivars which had golden yellow petal with the red coloration at the base.

All the cultivars presented fruits in erect position (Figure 2a) except Locale\#1 and Local\#3 which had fruits in completely drooping position (Figure $2 b$ ).
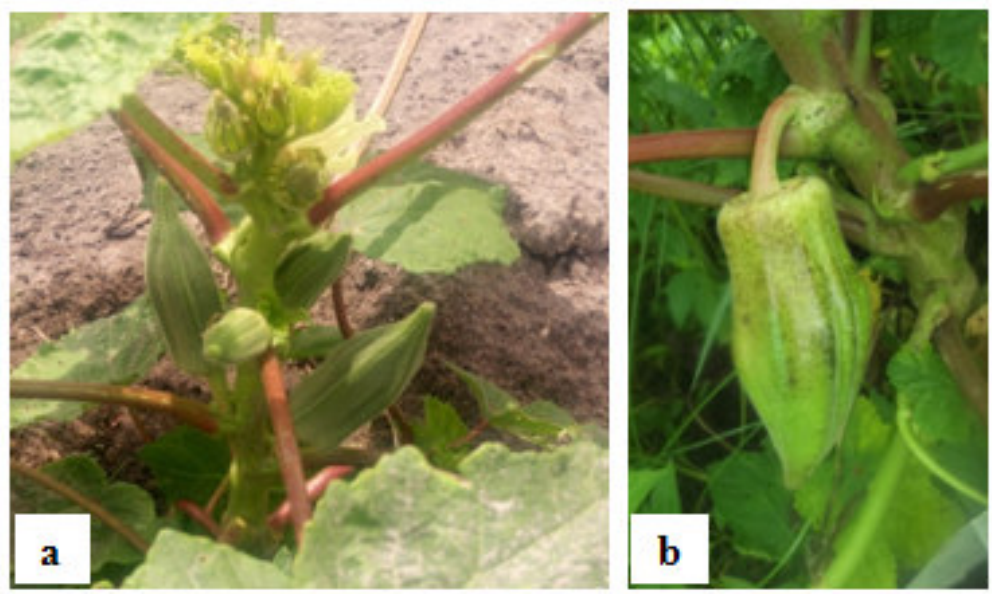

Figure 2. Two different positions of fruit observed in the okra cultivars studied: a) Fruit in erect position; b) Fruit in drooping position.

Apart from Emerald, Clemson and Local\#2 which had yellowish green fruits, all of the other genotypes had green fruits. A great variability in the shape of the fruits was observed (Figure 3).

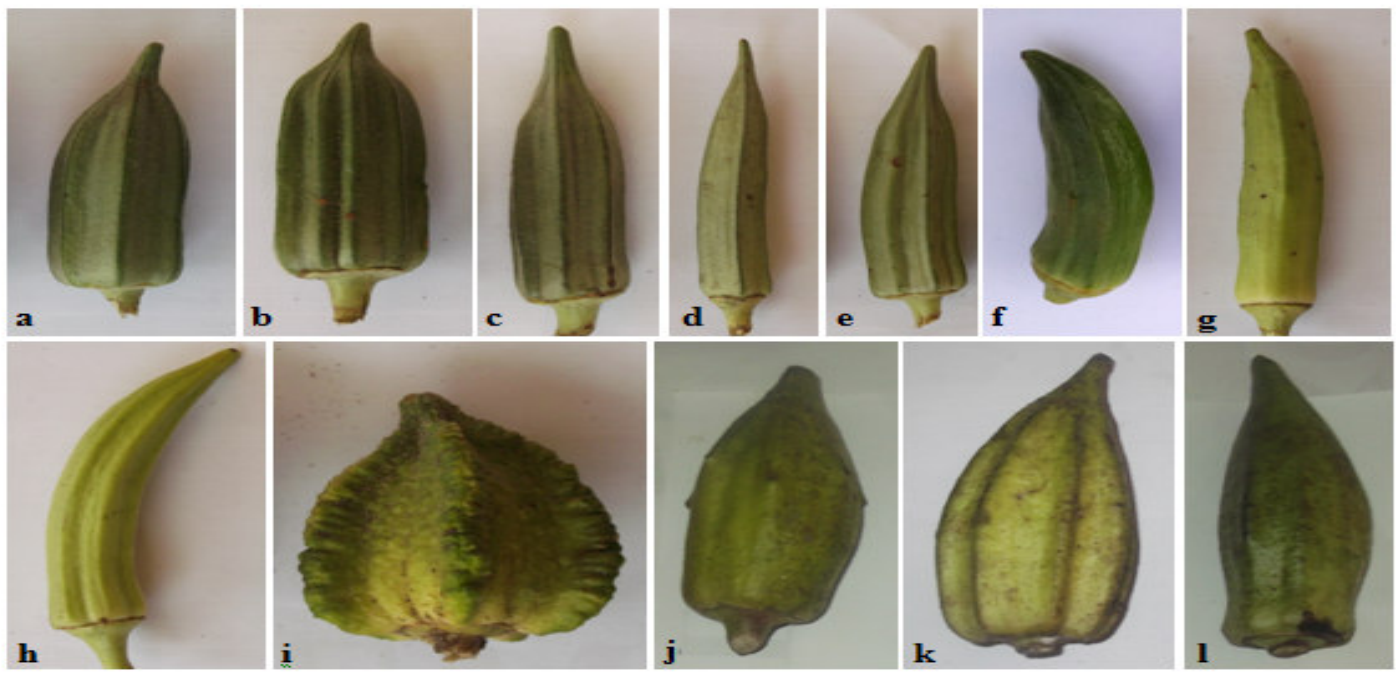

Figure 3: Fruit shapes of the okra cultivars studied: a) Hiré; b) Kirikou; c)Yelen; d)Volta; e)Yodana; f) Kousko; g) Emerald; h) Clemson; i) Cali; j) Local\#1; k) Local\#2; 1) Local\#3. 
These fruit shapes can be grouped into 8 types according to the descriptors of the International Plant Genetic Resources Institute (IPGRI, 1991): type 1 for Clemson; type 3 for Volta and Emerald; type 5 for Hiré, Yelen and Yodana; type 6 for Locale\#2; type 11 for Kousko; type 12 for Locale\#1 and Locale\#3; type 13 for Kirikou; and type 15 for Cali.

With the exception of Cali that had slightly rough fruits, all other cultivars had fruits that were lightly covered with down.

\subsection{Trait Associations}

The 12 quantitative traits and two qualitative traits (leaf and fruit shapes) which presented significant variations in the present study were submitted to a correlation study (Table 5).

\begin{tabular}{|c|c|c|c|c|c|c|c|c|c|c|c|c|c|c|}
\hline & SN & $\begin{array}{l}100 \\
\text { GW }\end{array}$ & DE & DF & SD & PH & FL & FD & FR & FW & FNP & FY & LS & FS \\
\hline SN & 1.00 & & & & & & & & & & & & & \\
\hline 100GW & -0.38 & 1.00 & & & & & & & & & & & & \\
\hline DE & -0.40 & 0.35 & 1.00 & & & & & & & & & & & \\
\hline DF & -0.78 & 0.49 & 0.76 & 1.00 & & & & & & & & & & \\
\hline SD & -0.81 & 0.61 & 0.72 & 0.95 & 1.00 & & & & & & & & & \\
\hline PH & -0.72 & 0.62 & 0.77 & 0.92 & 0.97 & 1.00 & & & & & & & & \\
\hline FL & -0.45 & 0.20 & 0.32 & 0.50 & 0.43 & 0.47 & 1.00 & & & & & & & \\
\hline FD & -0.72 & 0.42 & 0.59 & 0.79 & 0.86 & 0.81 & 0.01 & 1.00 & & & & & & \\
\hline FR & -0.04 & 0.37 & 0.69 & 0.49 & 0.52 & 0.54 & 0.06 & 0.43 & 1.00 & & & & & \\
\hline FW & -0.19 & 0.43 & 0.79 & 0.63 & 0.57 & 0.68 & 0.26 & 0.55 & 0.67 & 1.00 & & & & \\
\hline FNP & -0.02 & 0.80 & 0.51 & 0.32 & 0.40 & 0.53 & 0.00 & 0.29 & 0.51 & 0.62 & 1.00 & & & \\
\hline FY & -0.08 & 0.74 & 0.65 & 0.48 & 0.51 & 0.64 & 0.12 & 0.42 & 0.60 & 0.84 & 0.94 & 1.00 & & \\
\hline LS & -0.10 & -0.43 & -0.03 & -0.09 & -0.25 & -0.24 & 0.12 & -0.11 & -0.53 & 0.06 & -0.39 & -0.24 & 1.00 & \\
\hline FS & 0.63 & -0.28 & -0.36 & -0.55 & -0.52 & -0.42 & -0.56 & -0.28 & -0.36 & -0.20 & 0.05 & -0.03 & -0.02 & 1.00 \\
\hline
\end{tabular}

Table 5. Correlation coefficients among traits studied in the 12 okra cultivars.

SN: average number of seeds per fruit; 100SW: 100 seed weight; .DE: days to emergence; DF: days to flowering; SD: stem diameter at base; PH: plant height at flowering; FL: fruit length at maturity; FD: fruit diameter at maturity; FR: number of ridges per fruit; FW: average fresh fruit weight; FNP: number of fruits per plant; FYP: fresh fruit yield per plant; LS: leaf shape; FS: fruit shape.

The correlations for each pair of traits were assessed using the Pearson correlation coefficients. The matrix (Table 5) generated for the 14 traits revealed that several traits were positively correlated. Thus, plant height was strongly and positively correlated with day to flowering $(0.92)$, stem diameter $(0.97)$ and fruit diameter $(0.81)$; and it was moderately and positively correlated with number of fruits per plant $(0.53)$, fruit weight $(0.68)$, fruit yield (0.64), fruit ridges (0.54) and 100 seed weight (0.62). Day to flowering was highly and positively associated to day to emergence (0.76), plant height (0.92), stem diameter $(0.95)$ and fruit diameter (0.79); but it was positively and moderately associated with fruit weight $(0.63)$, fruit length $(0.50)$, number of fruit ridges $(0.49)$ and fruit yield (0.48). Fruit yield was positively and strongly associated with yield contributing traits such as number of fruit per plant (0.94), fruit weight per plant (0.84) and 100 seed weight (0.74). Stem diameter and fruit diameter were strongly and positively correlated (0.86). On the other hand, a strong negative correlation was observed between number of seeds and day to flowering $(-0.78)$, stem diameter $(-0.81)$, plant height $(-0.72)$ and fruit diameter $(-0.72)$.

\subsection{Principal Component Analysis (PCA)}

The principal component analysis (PCA) transformed the 14 raw set of data into 14 factors loadings or principal components, with the first principal component (PC1) contributing the most variability $(52.392 \%)$ and the last principal component (PC14) contributing the lowest variability $(0.055 \%)$. Eigen values are often used to determine how many Principal Components to retain. Usually Components with Eigen values less than 1 are excluded (Shah et al. 2018). The first four PC (PC1, PC2, PC3, and PC4) had Eigen values greater than 1, and showed therefore high significant variability compared to the rest of the PCs which had Eigen values less than 1. These latter PCs had not been considered, as they were not significantly influencing the variability among the cultivars. The percentage of variation explained by the first four PCs, their Eigen value and the factor scores for the 14 agromorphological traits are presented in Table 6. 
Table 6. Principal component analysis of 14 traits in the okra cultivars studied showing Eigen vectors, Eigen values, total and cumulative percentage of variance explained by the first four PC axes.

\begin{tabular}{|c|c|c|c|c|}
\hline TRAIT & PC 1 & PC 2 & PC 3 & PC 4 \\
\hline $\mathbf{S N}$ & 0.236 & -0.421 & 0.183 & -0.176 \\
\hline 100GW & -0.259 & -0.193 & -0.315 & -0.164 \\
\hline DE & -0.308 & -0.024 & 0.318 & 0.015 \\
\hline DF & -0.336 & 0.206 & 0.013 & 0.075 \\
\hline SD & -0.346 & 0.156 & -0.153 & 0.130 \\
\hline PH & -0.355 & 0.076 & -0.045 & 0.070 \\
\hline FL & -0.150 & 0.314 & 0.120 & -0.630 \\
\hline FD & -0.288 & 0.108 & -0.076 & 0.551 \\
\hline FR & -0.249 & -0.235 & -0.024 & -0.123 \\
\hline FWP & -0.288 & -0.163 & 0.463 & -0.003 \\
\hline FNP & -0.235 & -0.425 & 0.001 & -0.099 \\
\hline FY & -0.277 & -0.364 & 0.188 & -0.079 \\
\hline $\mathbf{L S}$ & 0.092 & 0.295 & 0.675 & 0.116 \\
\hline FS & 0.182 & -0.346 & 0.122 & 0.412 \\
\hline Eigen value & 7.335 & 2.534 & 1.251 & 1.073 \\
\hline Total variance (\%) & 52.392 & 18.097 & 8.935 & 7.663 \\
\hline Cumulative variance (\%) & 52.392 & 70.489 & 79.424 & 87.088 \\
\hline
\end{tabular}

Bold values are the highest contribution for each trait to total variance in the respective axes. SN: average number of seeds per fruit; 100SW: 100 seed weight; .DE: days to emergence; DF: days to flowering; SD: stem diameter at base; PH: plant height at flowering; FL: fruit length at maturity; FD: fruit diameter at maturity; FR: number of ridges per fruit; FW: average fresh fruit weight; FNP: number of fruits per plant; FYP: fresh fruit yield per plant; LS: leaf shape; FS: fruit shape.

These four PCs cumulatively explained $87.088 \%$ variation for the okra studied. The first two PCs together explained 70.489\% variation, comprising PC1 (52.392\% variation) with greater weightage on number of days to flowering, stem diameter, plant height and number of fruit ridges; and PC2 (18.097\% variation) with greater weightage on seed number, number of fruits per plant and fruit yield. The remaining variation $(16.599 \%)$ was contributed by the other two PCs (PC3 and PC4) with greater weightage on the rest of the traits. Thus, PC1 was mainly attributed to day to flowering and growth traits and PC2 to characters related to fruit and seed yields.

Biplot analysis was carried out based on the first two PCs. The traits and the cultivars were shown on the biplots (Figure 4 and Figure 5, respectively) to clearly visualize their associations and differences.

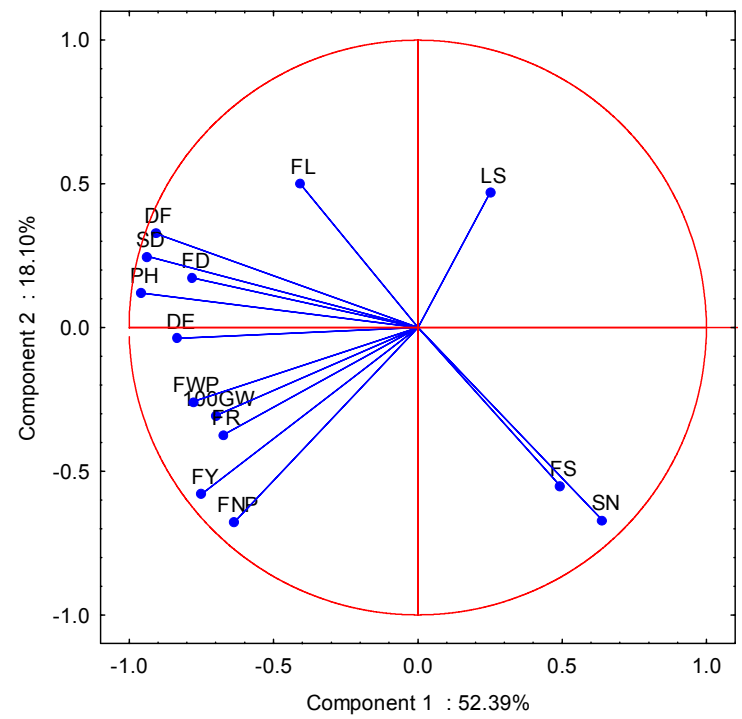

Figure 4. Plot of components weight of 14-morpho-agronomic traits of the okra cultivars studied. 


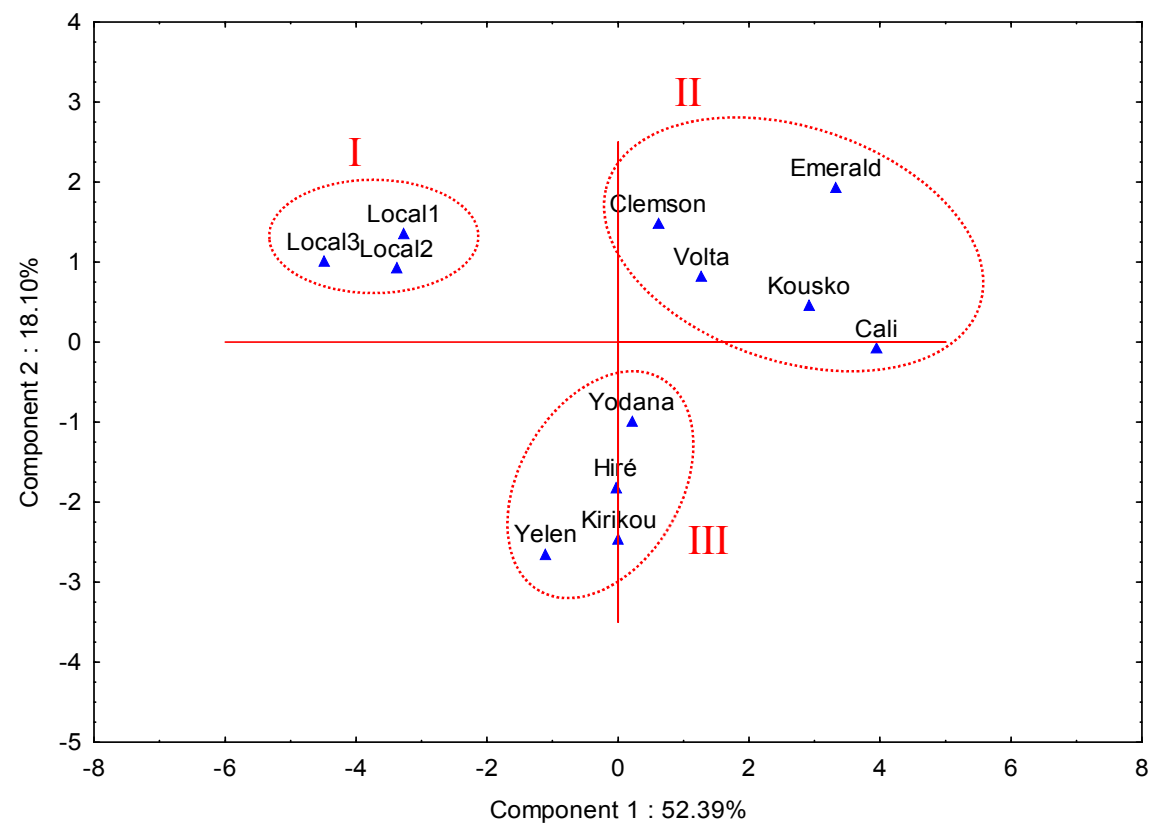

Figure 5. Scatter plot of the first and second principal component analysis for the okra cultivars studied, showing three clusters.

The scatter plot of the cultivars (Figure 5) presented the diversity pattern of the okra cultivars studied and classified them into three groups. The group I contained exclusively the local cultivars (Local\#1, Local\#2 and Local\#3). The group II comprised the cultivars Cali, Kousko, Volta, Clemson and Emerald; and the latest group (III) contained the cultivars Yelen, Kirikou, Hiré and Yodana.

\subsection{Genetic Distance and Cluster Analysis}

Genetic distance of the 12 okra cultivars was measured using Manhattan distance (city-block) based on the 14 selected traits and the result is presented in Table 7. The genetic distances for all the possible pairs of okra cultivars ranged from 17 to 277 with a mean of 119.259. The most distant pair of cultivars were Cali and Local\#3 (277) followed by Kousko and Local\#3 (261) and Emerald and Local\#3 (255). The lowest genetic distance was recorded between Hiré and Kirikou (17) followed by Kousko and Cali (31), and Emerald and Cali (41).

The average distance of each cultivar from the other cultivars was calculated to determine which cultivars were the most distant and closest to other cultivars. Local\#3 was the most distant cultivar from the others cultivars with a mean distance of 160; whereas Yodana and Clemson were found the closest to other cultivars with mean distances of 90 and 97, respectively.

The genetic distance within the $A$. esculentus cultivars ranged from 17 to 175 with a mean of 92; while the distance within $A$. caillei cultivars varied from 58 to 84 with a mean of 49 . The average distance between all cultivars of $A$. caillei and all cultivars of $A$. esculentus was 172.

The distance matrix (Table 7) was used to construct a dendrogram based on the Unweighted Pair-group Method with Arithmetic means (UPGMA). 
Table 7. Genetic distance matrix of the 12 okra cultivars measured using Manhattan distance (city-block).

\begin{tabular}{|c|c|c|c|c|c|c|c|c|c|c|c|c|}
\hline & 풍 & 젗: & $\frac{\nwarrow}{\varrho}$ & $\underset{Ð}{\stackrel{Ð}{\#}}$ & 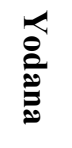 & $\begin{array}{l}\bar{\lambda} \\
\stackrel{\overline{0}}{\overline{0}} \\
\stackrel{0}{0}\end{array}$ & 色. & $\begin{array}{l}\stackrel{2}{3} \\
\frac{9}{2} \\
\frac{0}{2}\end{array}$ & 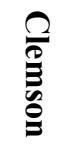 & 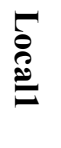 & $\begin{array}{l}5 \\
\stackrel{5}{N}\end{array}$ & \\
\hline Hiré & 0 & & & & & & & & & & & \\
\hline Kirikou & 17 & 0 & & & & & & & & & & \\
\hline Yelen & 53 & 49 & 0 & & & & & & & & & \\
\hline Volta & 142 & 146 & 148 & 0 & & & & & & & & \\
\hline Yodana & 74 & 77 & 78 & 72 & 0 & & & & & & & \\
\hline Kousko & 158 & 164 & 163 & 45 & 98 & 0 & & & & & & \\
\hline Cali & 160 & 167 & 175 & 56 & 118 & 31 & 0 & & & & & \\
\hline Emerald & 165 & 174 & 175 & 46 & 114 & 43 & 41 & 0 & & & & \\
\hline Clemson & 98 & 106 & 109 & 81 & 45 & 110 & 121 & 105 & 0 & & & \\
\hline Local1 & 154 & 159 & 169 & 155 & 112 & 185 & 199 & 181 & 93 & 0 & & \\
\hline Local2 & 121 & 122 & 128 & 182 & 123 & 215 & 230 & 208 & 129 & 77 & 0 & \\
\hline Local3 & 143 & 144 & 138 & 228 & 169 & 261 & 277 & 255 & 165 & 84 & 58 & 0 \\
\hline
\end{tabular}

The dendrogram drawn showed the relationships between the 12 cultivars studied (Figure 6 ). All the cultivars were distinct from each other but formed 3 major clusters at $60 \%$ level of similarity. Cluster I included Local\#1, Local\#2 and Local\#3; Cluster II comprised Volta, Kousko, Cali and Emerald; while cluster III contained the cultivars Hiré, Kirikou, Yelen, Yodana and Clemson. The genetic distance within Cluster II ranged from 31 to 56 with a mean of 33; while within cluster III it varied from 17 to 109 with a mean of 56. The inter cluster distances were 214.60 between cluster I and cluster II, 137.94 between cluster I and cluster III, and 137.72 between cluster II and cluster III.

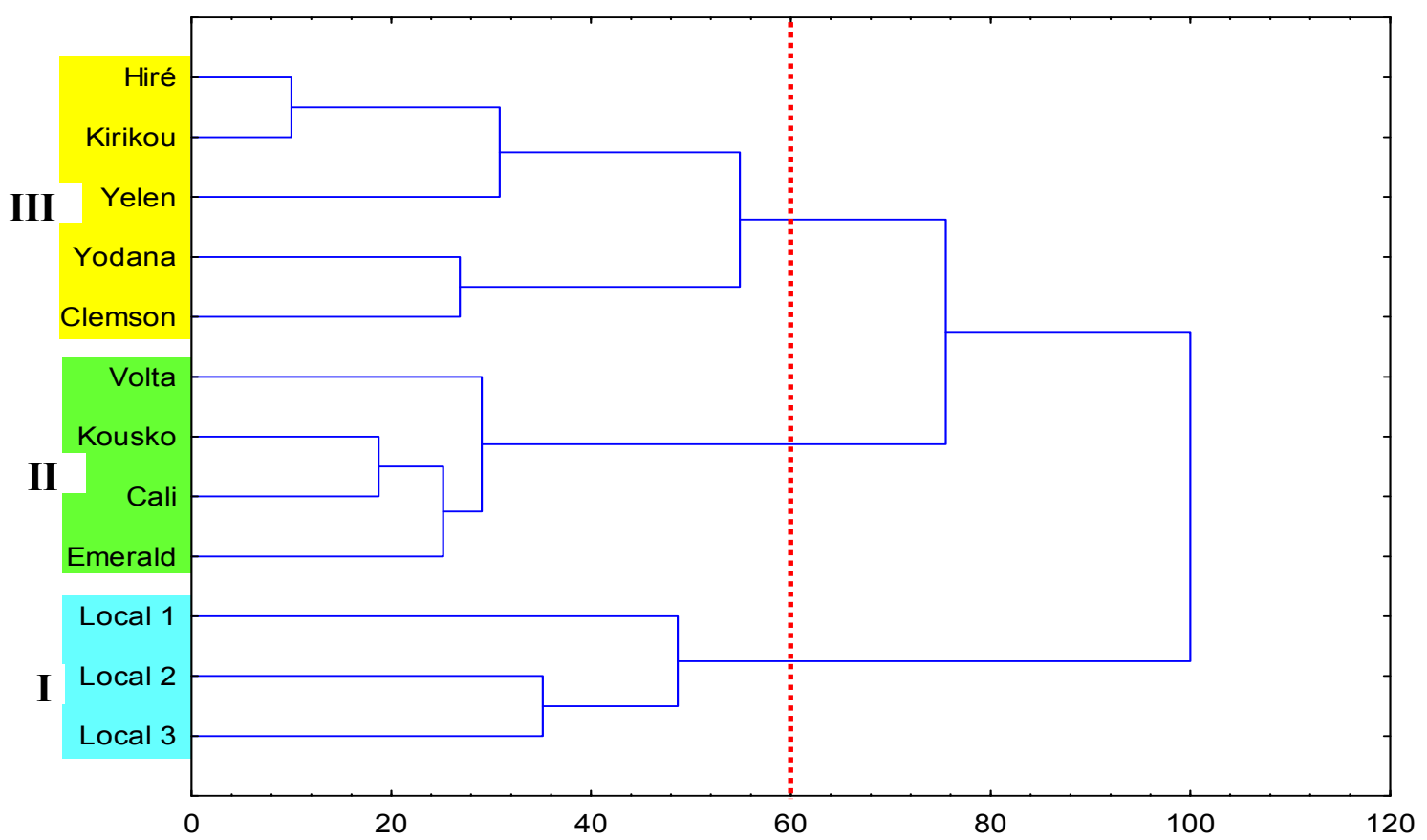

Figure 6. Dendrogram of Manhattan distance illustrating the genetic relationships among the 12 studied okra cultivars and showing 3 major clusters at $60 \%$ level of similarity.

\section{Discussion}

The evaluation of the 12 cultivars of okra using morpho-agronomic descriptors was done to provide information on genetic diversity within the crop in Côte d'Ivoire. Variability is very important for breeding programs. The okra cultivars evaluated showed wide variation in quantitative traits but minimal variation in qualitative traits except for leaf and fruit shapes. Amiteye et al. (2019) also found the same trend when studying okra genotypes from 
Ghana. This observation implies that quantitative traits are more useful for studying genetic diversity of okra germplasm than qualitative traits, as reported by Omalsaad et al. (2014).

Regarding the earliness, the cultivars differed significantly in the number of days to seedling emergence and days to plant flowering. Earliness in okra is determined by the number of days from sowing to flowering (Amiteye et al., 2019). Differences in flowering periods among the cultivars imply that their maturity periods vary (Eshiet $\&$ Brisibe 2015). The three local cultivars of $A$. caillei were later than all the cultivars of $A$. esculentus. This result is supported by Gangopadhyay et al. (2017) and Ogwu et al. (2018) who reported similar behavior of cultivars of A. caillei compared to A. esculentus. Based on the result of the present study, selection for earliness can be made using the earliest maturing cultivars of $A$. esculentus which are Kousko, Cali and Emerald. Early maturing cultivars could be selected for areas with short rainy seasons. Earliness is an important selection criterion in the current context of global climate change and shortening of the duration of rainy seasons in several regions.

The growth parameters studied also showed significant variation. For plant height, the cultivars belonging to A. caillei showed the highest mean values compared to the cultivars of A. esculentus. Similar observation was reported by Omonhinmin \& Osawaru (2005) with taller plants recorded for A. caillei $(34.50$ to $52.20 \mathrm{~cm})$ than for A. esculentus (21.30 to $30.10 \mathrm{~cm})$. Okra growth traits is of particular interest for breeding programs because tall plants and thin stems increase rate of lodging in windstorms or near harvesting time, and this can potentially affect yield (Amiteye et al. 2019). However, the cultivars of $A$. caillei showed the highest values of stem diameter, conferring to these cultivars a good vigor. The high height combined with the large stem diameter of these cultivars could represent interesting traits for the savannah areas in the north of Côte d'Ivoire, where okra is most often associated with tall cereals such as millet, sorghum and maize. In this type of cultural association, okra plants need to be tall to well integrate in the crop system because of the competition for light.

The fruit is considered as the most important and economical part of okra. Consequently, all traits linked to the fruit and its yield are very important (Eshiet \& Brisibe 2015). The results regarding the traits of fruits (fruit length, fruit diameter, fruit weight, fruit yield, number of ridges per fruit and fruit shape) showed important differences. The variation observed indicated that the cultivars studied were genetically different for these traits (Adeoluwa \& Kehinde 2011). Globally, the cultivars of $A$. caillei produced the greatest fruit caliber; while the cultivar Cali and Yelen of $A$. esculentus had the lowest fruit caliber. The range of fruit caliber presented by the germplasm studied allows the selection of a particular type of fruit according to the objectives of the breeding. Concerning the number of fruit and fruit yield per plant, the highest mean values were found in both cultivars of A. caillei and $A$. esculentus. But the cultivar Yelen of $A$. esculentus showed the highest average value of fruit number and fruit yield per plant. Hence, this cultivar appeared as an interesting cultivar in terms of production; and therefore it could be used as a good donor of this trait in okra breeding programs.

When the final objective of the culture is to extract the oil from the seeds or to use the seeds for other purposes, a good seed yield would be appreciable. Regarding mean seed numbers per fruit in this study, all the cultivars of A. esculentus had higher mean values than those of $A$. caillei. This result is supported by Gangopadhyay et al. (2017). However, the values of 100 seed weight were important in cultivars of A. caillei, especially in Local\#2 and Local\#3, probably because of the larger seeds of these cultivars. It is interesting to note that the cultivar Yelen of A. esculentus, in addition to its good fruit productivity, also presented an important value for the number of seeds per fruit and the weight of 100 seeds, indicating the double interest of this cultivar (important fruit and seed yields).

A correlation study was conducted on the traits which presented significant variation and the results showed several correlations between them. The analysis of the correlation between traits is important for breeding, especially for selection criteria. Lamine et al. (2014) and Gerrano (2018) mentioned that correlations between traits may correspond to a genetic linkage between loci controlling these traits or a pleiotropic effect. Thus, selection for a single trait may increase the trait values of positively correlated traits and decline the values for negatively correlated traits (Syfullah et al. 2018; Ahiakpa et al. 2013). This strategy allows the breeder for simultaneous selection and improvement of different phenotypic traits (Gerrano 2018). In the present study, the significant positive correlation of fruit yield with number of fruits per plant, fruit weight, plant height, fruit ridges and 100 seed weight indicated that selection for one of these traits would lead to a simultaneous improvement in yield per plant. Hence, these traits appear as good selection criteria for obtaining potential parents for the development of new high yielding cultivars.

In order to determine the pattern of dissimilarities and the genetic relationships between the okra cultivars evaluated, multivariate analyzes were performed through the simultaneous consideration of the 14 traits that presented significant variations. The use of multivariate techniques is an important strategy for estimating genetic diversity (Tadesse et al. 2018). According to Parvin et al. (2019) and Teodoro et al. (2019) more than one multivariate technique is required for a better diversity analysis, since each one has its own particularity. In the present investigation, two multivariate methods were used: Principal Component Analysis (PCA) and Cluster Analysis (CA). The results of PCA showed that $70.489 \%$ of the total variability among the okra studied was accounted for by the first two principal components. This result indicates that greater percentage of the total variance was explained by these two components. The first component is far more important, since it accounted 
for $52.392 \%$ of the variation, while the second accounted for $18.097 \%$. Four traits, viz. day to flowering, stem diameter, plant height and number of fruit ridges exhibited significant association with PC1, indicating that breeding in this component will lead to increase these parameters. Regarding PC2, the significant variables were three traits, viz. number of fruits per plant, fruit yield and number of seeds per fruit, which suggests increased values of fruit and seed yield when breeding in component 2 . These seven traits characterizing the first two PCAs can be considered the most important for the discrimination of the okra cultivars studied (Amiteye et al. 2019). This implies that high priority be given to these traits in future breeding programs.

PCA grouped all the 12 okra cultivars studied in three distinct clusters in a dimensional map. This result was confirmed by CA with the dendrogram that grouped the okra cultivars under three major clusters. Only Clemson seemed to straddle both cluster II and III when considering the two pattern of clustering, suggesting that this cultivar shared the characteristics of these two clusters. Clustering is a technique that can conveniently show the pattern of genetic relationships or proximity among the cultivars studied such that each group is homogeneous with respect to certain characteristics and each group should be different from other groups with respect to the same characteristics (Gangopadhyay et al. 2017). Thus, the late maturing and tall cultivars of A. caillei were grouped into cluster I. They produced relative important yield next to cluster III. In contrast, low performing and early maturing cultivars of $A$. esculentus were grouped into cluster II. This group contains genotypes with relatively small plant height, early days to flowering associated with relative low yield. Cluster III is the group with the highest performing cultivars, hence it can be considered as a base population in yield improvement programs. It was characterized by intermediate early maturing and plant height, but higher fruit and seed yield. This cluster also exhibited the highest intra cluster distance (56 against 49 and 33 for respectively cluster I and II), indicating a relative higher divergence among the cultivars it comprised. This relative wider genetic variation of cluster III accompanied with it useful characteristics regarding yield, confirm the interesting status of this cluster as a base population for a future breeding program.

The fact that the cultivars of $A$. caillei were grouped in the same cluster (cluster-I) reveals their close relationship. Gangopadhyay et al. (2017) reported similar grouping of accessions of $A$. caillei in one cluster, indicating higher degree of morphological similarity among them. The clear distinction between the A. caillei cultivars and $A$. esculentus cultivars highlights the different genetic background of these two species and the independent identity of each of them. This result confirms the finding of Aladele et al. (2008) who reported distinct clustering between $A$. caillei and A. esculentus. Contrarily to A. caillei, the cultivars of $A$. esculentus were separated into two clusters (cluster II and cluster III), showing the existence of a larger genetic variability in the $A$. esculentus cultivars. This is supported by the wider genetic distance obtained with A. esculentus cultivars (92) compared to A. caillei (49).

The inter cluster distances were important between the clusters (214.60 for cluster1/cluster2, 137.94 for cluster1/cluster3, and 137.72 for cluster2/cluster3). These high magnitudes of inter-cluster distances were indicators for the presence of a substantial genetic diversity in the okra studied. Success of any crop improvement programs mainly depends on amount of diversity available in the crop. Increasing parental distance implies a great number of contrasting alleles at the desired loci; and a crossing of cultivar from distantly clusters may produce higher amount of heterotic expression in the first generations (F1) and wide range of variability in subsequent segregating (F2) populations, offering the opportunities for the effective breeding for superior genotypes (Shah et al. 2018; Tadesse et al. 2018). Therefore, in this study, the important genetic distance among the clusters suggests the possibility of improving the crop through the use of cultivars grouped in distant clusters as parents for hybridization. This fact would result in progenies with a broad genetic base and a higher probability of obtaining new genetic combinations with useful characteristics in segregating generations (Teodoro et al. 2019). In addition to the genetic distance, the selection of the parents should also consider the special advantage of each cluster and each genotype within a cluster depending on the objective of hybridization (Gangopadhyay et al. 2017). Each of the three clusters of this study exhibited a main specific interesting trait: vigor and good yield for cluster I, short plants and earliness for cluster II and high yield for cluster III. This offers the possibility of improving the crop by pyramiding the useful genes of each cluster in a new genotype. For this, the use of the best cultivar from each of the three clusters in a hybridization program could generate the expectation of obtaining hybrids with a greater heterotrophic effect.

Finally, the extent of diversity present in the okra germplasm evaluated and the interesting useful traits they presented, give the hope of an improvement through the selection and hybridization of agronomically promising genotypes.

\section{Conclusion}

The current study showed a high level of variations in 14 agromorphological traits among the 12 okra cultivars evaluated. Seven traits (day to flowering, stem diameter, plant height, number of fruit ridges, number of fruits per plant, fruit yield and number of seeds per fruit) were identified as playing a prominent role in the differentiation of the okra cultivars and could be used as good criteria for selection in okra improvement. Multivariate analyses 
were able to group the total cultivars into three divergent clusters exhibiting specific characteristics: vigor and good yield for cluster I, short plants and earliness for cluster II and high yield for cluster III. The best genotypes of these clusters represent interesting parental material for further breeding to produce desirable recombinants. Thus, the local cultivars of $A$. caillei could be useful in breeding programs where vigorous plants with a good crop yield are the dominant desire. Conversely, the A. esculentus okra cultivars of cluster II would be preferable where shorter and early maturing plants are desired. And finally cultivars of $A$. esculentus from cluster III, especially Yelen will be adequate parent in breeding for high yield.

The findings of this study provided credence to the relevance of using agro-morphological descriptors to estimate plant genetic diversity. Nevertheless, this ago-morphological investigation may be complemented by more reliable means such as molecular and biochemical tools.

\section{References}

Adeoluwa, O., \& Kehinde, O. (2011), "Genetic variability studies in West African okra (Abelmoschus caillei)", Agriculture and Biology Journal of North America 2, 1326-1335.

Ahiakpa, J.K., Magdy, M., Werner, O., Amoatey, H.M., Yeboah, M.A., Appiah, A.S., Quartey, E.K, \& Ros, R.M. (2017), "Intra-specific variation in West African and Asian germplasm of okra (Abelmoschus spp L.)", Annals of Agricultural Science 62, 131-138.

Aladele, S.E., Ariyo, O., de Lapena, R. (2008), "Genetic relationships among West African okra (Abelmoschus caillei) and Asian genotypes (Abelmoschus esculentus) using RAPD”, African Journal of Biotechnology 7, 1426-1431.

Amiteye, S., Amitaaba, T., \& Amoatey, H.M. (2019), "Morphological Characterization of Accessions of Okra (Abelmoschus Spp L.)", International Journal of Pure \& Applied Bioscience 7(1), 1-13.

Binalfew, T., \& Alemu, Y. (2016), "Characterization of Okra (Abelmoschus esculentus (L.) Moench) Germplasms Collected from Western Ethiopia", International Journal of Research in Agriculture and Forestry 3(2), 11-17.

Eshiet, A.J., \& Brisibe E.A. (2015), "Morphological Characterization and Yield Traits Analysis in Some Selected Varieties of Okra (Abelmoschus Esculentus L. Moench)", Advances in Crop Science and Technology 3(5), 1-5. doi:10.4172/2329-8863.1000197

FAOSTAT '2020), "Food and Agriculture Organization of the United Nations, Statistics Division. Data for over 245 countries and territories and covering all FAO regional", http://www.fao.org/faostat/en/\#home.

Gangopadhyay, K.K., Singh, A.,. Bag, M.K., Ranjan P., Prasad, T.V., Roy, A., \& Dutta, M. (2017), "Diversity analysis and evaluation of wild Abelmoschus species for agro-morphological traits and major biotic stresses under the north western agro-climatic condition of India”, Genetic Resources and Crop Evolution 64, 775790.

Gerrano, A.S. (2018), "Agronomic Performance, Nutritional Phenotyping and Trait Associations of Okra (Abelmoschus esculentus) Genotypes in South Africa, Rediscovery of Landraces as a Resource for the Future", IntechOpen. DOI: 10.5772/intechopen.70813. Available from: https://www.intechopen.com/books/rediscovery-of-landraces-as-a-resource-for-the-future/agronomicperformance-nutritional-phenotyping-and-trait-associations-of-okra-abelmoschus-esculentus-

IPGRI (1991), “Okra Descriptor list”, International Crop Network Series 5, International Board for Plant Genetic Resources (IBPGR), Rome, Italy.

Kumari, M., Solankey, S.S., Kumar, K., Kumar, M., \& Singh, A.K. (2019), "Implication of Multivariate Analysis in Breeding to Obtain Desired Plant Type of Okra (Abelmoschus esculentus L. Moench)", Current Journal of Applied Science and Technology 36(4), 1-8. https://doi.org/10.9734/cjast/2019/v36i430248

Lamine, M., Zemni, H., Ziadi, S., Chabaane, A., Melki, I., Mejri, S., \& Zoghlami, N. (2014), "Multivariate analysis and clustering reveal high morphological diversity in Tunisian autochthonous grapes (Vitis vinifera): insights into characterization, conservation and commercialization", OENO One 48(2), 111-122. https://doi.org/10.20870/oeno-one.2014.48.2.1565.

Marcelline, G., Hounnankpon, Y., Cossi, A., Hurgues, H., \& Nestor, D. (2018), "Specific and Phenotypic Diversity of Okras Grown in Benin, West Africa", Scholars Journal of Research in Agriculture and Biology 3(1), 178198.

Ogwu, M.C., Onosigbere-Ohwo, U., \& Osawaru, M.E. (2018), "Morphological Characterization of Okra (Abelmoschus [Medik.]) Accessions", Makara Journal of Science 22(2), 67-76. DOI: 10.7454/mss.v22i2.

Omalsaad, A. K. M., Aminul, I., Murshida, A.J., Zahira, Y., \& Mohamad, O., (2014), "Genetic relationship between roselle (Hibiscus sabdariffa L.) and kenaf (Hibiscus cannabinus L.) accessions through optimization of PCR based RAPD method", Journal of Food and Agriculture. 26(3), 247-258.

Omonhinmin, C.A., \& Osawaru M.E. (2005), "Morphological characterization of two species of Abelmoschus: Abelmoschus esculentus and Abelmoschus caillei", Plant Genetic Resources Newsletter 144, 51-55.

Oppong-Sekyere, D., Akromah, R., Nyamah, E.Y., Brenya, E., \& Yeboah, S. (2018), "Characterization of okra (Abelmoschus spp. L.) germplasm based on morphological characters in Ghana", African Journal of Crop 
Science 6(5), 1-11.

Parvin, E., Mahmud, F., Shahidur, M., Bhuiyan, R., \& Haque M.M. (2019), "Multivariate Analysis of Genetic Variation in Rapeseed (Brassica Napus L.)", Agriculture and Food Sciences Research 6(1), 1-8.

Shah, I.A., Khan, I., Mir, S.A., Pukhta, M.S., Dar, Z. A., \& Lone, A. (2018), "Genetic Diversity by Multivariate Analysis Using R Software", International Journal of Pure \& Applied Bioscience 6(3), 81-190.

Syfullah, K., Sani, M.N.H., Nasif, S.O., Parvin, S., Rony, M.M.H., Islam, M.S., \& Hossain, M.S. (2018), "Genetic Variability, Heritability, Character Association and Morphological Diversity in Okra (Abelmoschus esculentus L. Moench)", International Journal of Plant \& Soil Science 25(6), 1-11. https://doi.org/10.9734/IJPSS/2018/45828

Tadesse, L., Mekbib, F., Wakjira, A., \& Tadele, Z. (2018), "Multivariate Analysis of Genetic Diversity in the Ethiopian Garden Cress (Lepidium sativum L.) Genotypes", Journal of Experimental Agriculture International 27(3), 1-16.

Temam, N., Mohamed, W., \& Aklilu, S. (2020), “Agro morphological Characterization and Evaluation of Okra [Abelmoschus esculentus (L.) Moench] Genotypes for Yield and Other Variability Components at Melkassa, Central Ethiopia”, MOJ Ecology \& Environmental Sciences 5(2), 80-87.

Teodoro, R.L.P., Evangelista, J.S.P.C., Damacena, M.B., Elizeu, A.M., Coelho, I.F., Rodrigues, E.V., Teodoro, P.E., \& Bhering, L.L. (2019), "Estimates of genetic divergence in cowpea by multivariate analysis in different environments”, Bioscience Journal 35(6), 1681-1687. https://doi.org/10.14393/BJ-v35n6a2019-42406. 